\title{
Resenha crítica de filmes: desenvolvendo habilidades de leitura em língua portuguesa
} com alunos surdos

\author{
Critical review of movies: developing portuguese language reading skills with deaf students \\ Reseña crítica de película: desarrollo de las destrezas de lectura en lengua portugués con \\ estudiantes sordos
}

\section{Resumo}

A resenha é um gênero bem presente no nosso cotidiano e propício para se trabalhar em aulas de Língua Portuguesa, uma vez que tal gênero poderá proporcionar ao leitor informações que lhe ajudarão na análise da obra, contribuindo, dessa forma, para a escolha ou não da compra/leitura. A propósito disso, este trabalho tem como objetivo analisar o gênero textual resenha crítica de filmes como ferramenta para o desenvolvimento das habilidades de leitura em Língua Portuguesa com aluno surdo. Tem como fundamentação teórica os estudos de Machado; Mascarello e Bakhtin. Nesse sentido, estudos como este, justificam-se por ampliar a discussão acerca da importância do uso do referido gênero nas aulas de Língua Portuguesa. Além disso, o trabalho se mostra relevante, por tratar da inclusão de estudantes surdos. Dessa forma, a pesquisa contribui no sentido de incentivar práticas pedagógicas para favorecem a leitura críticas dos estudantes surdos. Os resultados mostraram que o trabalho com resenha crítica de filmes poderá ser uma boa estratégia para que os alunos surdos desenvolvam habilidades de leitura em Língua Portuguesa.

Palavras-chave: Libras; Ensino; Resenha crítica; Leitura e análise; Língua portuguesa.

\begin{abstract}
The review is a genre that is very present in our daily lives and suitable for working in Portuguese Language classes, since this genre can provide the reader with information that will help them in the analysis of the work, thus contributing to the choice or not of the purchase/read. In this regard, this work aims to analyze the textual genre critical review of films as a tool for the development of reading skills in Portuguese with deaf students. Its theoretical basis is the studies by Machado; Mascarello and Bakhtin. In this sense, studies like this one are justified by expanding the discussion about the importance of using this genre in Portuguese language classes. In addition, the work is relevant, as it deals with the inclusion of deaf students. Thus, the research contributes towards encouraging pedagogical practices to favor deaf students' critical reading. The results showed that working with a critical review of films can be a good strategy for deaf students to develop reading skills in Portuguese.
\end{abstract}

Keywords: Libras; Teaching; Critical review; Reading and analysis; Portuguese language.

\section{Resumen}

La reseña es un género muy presente en nuestra vida diaria y apto para trabajar en las clases de lengua portuguesa, ya que este género puede proporcionar al lector información que le ayudará en el análisis de la obra, contribuyendo así a 
la elección o no de la compra / lectura. En este sentido, este trabajo tiene como objetivo analizar el género textual de revisión crítica de películas como herramienta para el desarrollo de las habilidades lectoras en portugués con estudiantes sordos. Su base teórica son los estudios de Machado; Mascarello y Bakhtin. En este sentido, estudios como este se justifican ampliando la discusión sobre la importancia de utilizar este género en las clases de lengua portuguesa. Además, el trabajo es relevante, ya que trata de la inclusión de estudiantes sordos. Así, la investigación contribuye a fomentar prácticas pedagógicas que favorezcan la lectura crítica de los estudiantes sordos. Los resultados mostraron que trabajar con una revisión crítica de películas puede ser una buena estrategia para que los estudiantes sordos desarrollen habilidades de lectura en portugués.

Palabras clave: Libras; Enseñanza; Revisión crítica; Lectura y análisis; Lengua portuguesa.

\section{Introdução}

$\mathrm{Na}$ escola, a resenha pode se fazer presente de diferentes formas, inclusive como recurso para desenvolver a criticidade dos estudantes. Em nosso estudo, mais especificamente, trabalharemos com a perspectiva dos alunos surdos aprendizes da Língua Portuguesa na modalidade escrita como segunda língua.

No Brasil, 9,7 milhões de pessoas são surdas ou têm deficiência auditiva. Razão pela qual justificamos essa discussão, que consistiu do gênero resenha crítica de filmes, na perspectiva de destacar os aspectos do referido gênero, a exemplo dos argumentos críticos da análise de elementos e dos questionamentos presentes na resenha, no sentido de despertar e desenvolver a leitura crítica dos surdos.

Reconhecendo a importância dessa discussão, este texto tem como objetivo analisar o gênero textual resenha crítica de filmes como recurso para o desenvolvimento de habilidades de leitura em Língua Portuguesa com alunos surdos. Sendo assim, buscamos incentivar a reflexão sobre de que forma a leitura de resenhas críticas de filmes pode contribuir para o desenvolvimento da criticidade do aluno surdo em relação às produções cinematográficas que trata sobre a comunidade surda.

Para alcançar este objetivo, selecionamos, a partir de tais critérios, as seguintes resenhas críticas: "A Família Bélier: emocionante filme francês sobre família de surdos" de Maurício Mellone; "A Família Bélier - Todo sonho é possível" de Bruno Carmelo; e "A família Bélier: um filme para fugir do óbvio" de Juliana Varella. Importa ainda destacar que foram selecionadas duas resenhas críticas positivas e uma negativa para que os alunos pudessem perceber os diferentes pontos de vista dos resenhistas sobre o mesmo filme e fazer suas próprias análises.

Este texto está organizado da seguinte forma: introdução, seguida da primeira seção que trata do contexto educacional da pessoa surda, além das leis e decretos voltados para essas pessoas. Na terceira seção, a leitura como habilidade, logo depois, abordamos a resenha crítica de filmes como possibilidade de favorecer o ensino de Língua Portuguesa para alunos surdos. Em seguida, trouxemos o Letramento crítico, a metodologia, a análise das resenhas e, por fim, as considerações finais.

\section{Metodologia}

A seguinte pesquisa está caracterizada como uma análise qualitativa e teve como corpus resenhas pesquisadas na internet. Optamos pela a pesquisa qualitativa, porque esta é apontada por teóricos como de grande relevância no estudo das ciências sociais e humanas, uma vez que possibilita a apreensão de vários aspectos no movimento real em que o fato, o fenômeno ou processos ocorrem (Flick, 2009).

A abordagem se deu a partir das análises de resenhas críticas dos filmes elencados neste estudo que foram coletadas em sites diversos na internet. Assim, Minayo (2008, p. 57) diz que, a pesquisa qualitativa "é adequada aos estudos da história, das representações e crenças, das relações, das percepções e opiniões, ou seja, dos produtos das interpretações que os humanos fazem durante suas vidas". 
As resenhas selecionadas foram as seguintes: "A Família Bélier: emocionante filme francês sobre família de surdos" de Maurício Mellone, "A Família Bélier - Todo sonho é possível" de Bruno Carmelo e "A família Bélier: um filme para fugir do óbvio" de Juliana Varella.

Procuramos selecionar duas resenhas críticas positivas e uma negativa para que os alunos pudessem perceber os diferentes pontos de vista dos resenhistas e pudessem tirar suas próprias conclusões a respeito do filme.

A seguir, mostraremos as resenhas, trechos das resenhas que podem despertar a criticidade nos alunos.

\section{Resultados}

Nesta seção, tratamos, de forma breve, do contexto da inclusão escolar da pessoa surda, no sentido de evidenciar os avanços conquistados por essas pessoas, a exemplo das leis que possibilitam a inclusão.

A pessoa surda é quem nasce surda, isto é, com a perda total da capacidade de ouvir. Ela faz parte e cresce a partir de um processo cultural diferente, pois a identidade surda e a sua representatividade fazem parte de uma maneira distinta de participar da sociedade (Cunha, Nyamien, 2020).

Os alunos surdos devem ter suas especificidades linguísticas e seus traços de identidade cultural respeitados, para, assim, se sentirem, de fato incluídos, uma vez que a presença física na escola, não significa inclusão. A inclusão desse aluno vai muito além dessa inserção na sala de aula. Quadros (2019, p.158) contribui dizendo que, "A educação bilíngue reconhece as diferenças entre as línguas, as diferenças textuais, linguística e políticas implicadas pelas comunidades envolvidas: as comunidades surdas e as comunidades ouvintes locais reconhecem suas culturas, identidades e línguas (Quadros, 1997; Svartholm, 2010)". Para se ter uma inclusão, que possa incluir a pessoa surda, necessariamente precisa-se incluir a Libras como Língua para interação, e o português para o desenvolvimento da escrita como L2 para pessoa surda.

Nesse sentido, Fabrício, Souza e Zimmermann (2007) afirmam que não adianta inserir o aluno deficiente, na sala de aula, se não houver preparo institucional e pessoal do professor. Dessa forma, para que a inclusão da pessoa surda ocorra, é preciso que o sistema de ensino tenha recursos educacionais especiais para atender às necessidades educacionais do surdo, e assim, sua língua tenha uma comunicação como qualquer outra língua. No entanto o surdo possa desenvolver o português com melhores entendimento de quem o ensina.

A inclusão pode acontecer com o desenvolvimento de estratégias que procuram proporcionar igualdade de oportunidades e que o princípio da escola inclusiva está no aprendizado da pessoa com deficiência, independente das diferenças que possa ter. No que concerne aos alunos surdos, para que estes sejam realmente incluídos, as escolas devem reconhecer as necessidades destes alunos, assegurando uma educação de qualidade a todos, através de currículo apropriado, modificações organizacionais e estratégias de ensino.

Neste contexto educacional da pessoa surda, a escola inclusiva poderá oferecer respostas aos desafios apresentados no processo de ensino aprendizagem dos alunos matriculados, procurando estratégias que favoreçam o desenvolvimento de habilidades desses alunos, a exemplo, do que está sendo sugerido nesse estudo, o trabalho com resenha crítica de filmes. Batista e Mantoan (2007) define que aprender é uma ação humana individual, criativa, heterogênea e é regulada por quem está aprendendo, ou ensinando independentemente de sua condição intelectual.

\subsection{Leis que asseguram os direitos às pessoas surdas}

No que se refere a surdez e a deficiência auditiva, a seguir, evidenciam-se leis e decretos criados exclusivamente para a pessoa surda ou com deficiência auditiva, a partir do ano 2000. 
Lei $\mathrm{n}^{\circ}$ 10.098, de 19 de dezembro de 2000 foi criada no sentido de estabelecer normas gerais e critérios básicos para a promoção da acessibilidade. A lei garante a acessibilidade do mobiliário urbano, como por exemplo, acesso a prédios públicos ou privados (estacionamentos, vagas, banheiros acessíveis, elevadores, percurso acessíveis, entre outros (BRASIL, 2000).

Lei $n^{\circ}$ 10.436, de 24 de abril de 2002 foi criada a fim de reconhecer a Libras, em termos legais, como meio de comunicação oficial das pessoas surdas e deficientes auditivas do Brasil. A referida lei, ainda, enfatiza a garantia que as instituições públicas e departamentos de assistência à saúde devem garantir meios para o atendimento à pessoa surda (Brasil, 2002).

Seguindo essa trajetória, foi criado o Decreto $\mathrm{n}^{\circ}$ 5.626, de 22 de dezembro de 2005 para regulamentar a Lei 10.436 (2002) e o Art. 18 da Lei 10.098 (2000) e com isso garantir a inserção da Libras como disciplina curricular obrigatória nos cursos de magistério, licenciaturas e fonoaudiologia do sistema de ensino público e privado. A mesma lei, ainda, aponta o processo de formação dos docentes, profissionais da Libras e intérpretes. Com essa nova regulamentação, o Decreto define o deficiente auditivo, perante a lei, na escala decibéis de escuta.

Outra importante lei foi a de $\mathrm{n}^{\mathrm{o}} 12.319$, de $1^{\mathrm{o}}$ de setembro de 2010 , a qual regulamenta a profissão de Tradutor e Intérprete de Libras e como deverá ser feita a formação destes profissionais, no sentido de saber quais os cursos regulamentados por lei e pela pasta da educação, banca avaliadora, certificação, exame de proficiência entre outros. Além de apontar quais são as atribuições da profissão (Brasil, 2010).

Mais recentemente foi criada a Lei n 13.146, de 6 de julho de 2015, conhecida como a Lei Brasileira de Inclusão (LBI). A citada lei se constitui como algo muito importante nesse contexto da inclusão da pessoa surda, dentre as leis que regem a educação especial e a inclusão da pessoa com deficiência na sociedade. Ou seja, é um documento completo, que garante direitos educacionais, civis, de saúde, habilitação e reabilitação. Destacando-se o direito à vida, educação, ao casamento, moradia, trabalho, assistência social, esporte, turismo, lazer, transporte, informação, comunicação, justiça e participação na vida pública e política (Brasil, 2015).

Diante disso, é possível dizer que estas leis e decretos contribuem de forma substancial para a mudança de concepção que a sociedade tinha em relação ao surdo, isto é, essa concepção vem-se modificando no decorrer da história. Para Goldfeld (2002) a ideia que a sociedade fazia dos surdos era, normalmente, negativa. Tal concepção decorria da antiguidade, quando os surdos eram vistos com piedade e compaixão que eram surdos por castigos pelos deuses ou eram concebidos como pessoas enfeitiçadas, e por isso eram abandonados ou sacrificados.

Portanto, a mudança de visão a respeito da pessoa surda é algo muito importante para a inclusão de surdo no contexto educacional e consequentemente na sociedade, para isso, as leis e decretos devem ser respeitadas, uma vez que a inclusão de pessoas deficientes e dentre estas, a pessoa surda, ainda se constitui em desafio.

\subsection{A leitura como uma habilidade}

A leitura como habilidade vem sendo objeto de preocupação dos documentos oficiais que regem a educação no Brasil, exemplo disso, é concepção de leitura trazida pelos PCNs que propõem a leitura como um processo no qual "o leitor realiza um trabalho ativo de construção do significado do texto, a partir dos seus objetivos, do seu conhecimento sobre o assunto, sobre o autor, de tudo o que sabe sobre a língua" (Brasil, 1997, p.41). Isso significa que a leitura vai além de apenas extrair informação da escrita, isto é, ela é uma atividade que implica, a construção dos sentidos. Para uma leitura fluente é preciso uma série de outras estratégias como seleção, antecipação, inferência e verificação, sem as quais não é possível rapidez e proficiência (Solé, 1998). 
É importante destacar que a leitura como uma habilidade deve ser desenvolvida, ao longo do processo de ensino e aprendizagem, dentre essa estratégia, é possível desenvolver a leitura crítica, a qual sugerimos, neste estudo, que seja desenvolvida, no contexto escolar, tendo como possibilidade o uso da resenha crítica de filmes. Dessa forma, procuramos refletir sobre o referido gênero no sentido de uma leitura que pode servir como base para as práticas que conduzem a um ensino aprendizagem mais significativo em aulas de Língua Portuguesa para alunos surdos. A esse respeito, Silva (1981) afirma que a leitura crítica sempre leva à produção de textos críticos, isso ocorre quando esse tipo de leitura é muito mais do que um simples processo de apropriação de significado.

Corroborando esse entendimento, Rojo e Moura (2012), referem que a leitura deve ser o eixo norteador de todo processo de ensino e aprendizagem, sendo assim, deve ser uma prática voltada para a formação de leitores e não de "alfabetizados". Isto significa que ler não é apenas decodificar, se assim for, o leitor não terá condições de assumir um posicionamento perante aquilo que leu.

Segundo dados sobre a leitura no Brasil publicada em 11 de setembro de 2020, pouco mais da metade do país 52\% tem hábitos de leitura. Segundo a pesquisa, a Bíblia e livros religiosos dominam a preferência e conforme a mesma pesquisa o Brasil perdeu 4,6 milhões de leitores em quatro anos entre 2015 e 2019 e com queda puxada para mais riscos. O resultado é 4\% menor do que o registrado em 2015, quando a porcentagem de leitores no país era de 56\%. A média de livros inteiros lidos em um ano se manteve estável: 4,2 livros por pessoa (Tokarnia, 2020).

Como dizia Carlos Drummond de Andrade (1987, [s.p.]) "A leitura é uma fonte inesgotável de prazer, mas por incrível que pareça, a quase totalidade, não sente esta sede". Podemos perceber que não é algo que desperta o interesse da maioria da população, ela atinge apenas $52 \%$ segundo a pesquisa.

A Base Nacional Comum Curricular (BNCC) diz que a leitura em sua habilidade 44 para o Ensino Fundamental do $6^{\circ}$ ao $9^{\circ}$ ano do Componente Curricular de Língua Portuguesa (EF69LP44) tem como objetivo "Inferir a presença de valores sociais, culturais e humanos e de diferentes visões de mundo, em textos literários, reconhecendo nesses textos formas de estabelecer múltiplos olhares sobre as identidades, sociedades e culturas e considerando a autoria e o contexto social e histórico de sua produção". Desta forma trabalhar com gêneros textuais é oportunizar aos alunos experiências culturais e intelectuais sobre seu olhar sobre o mundo e por tudo aquilo que é produzido pelas pessoas.

A leitura de resenhas críticas de filmes torna possível aos alunos conhecer esta visão sobre um produto cultural que está impregnado de visões sobre o contexto social destas produções. Compreender e utilizar a língua portuguesa em situações comunicativas apresentadas em diferentes gêneros e tipologias, a partir da leitura e análise das resenhas críticas de filmes é imprescindível para que se desenvolva a habilidade de leitura através destas produções escritas. No qual Alves (2020), apresenta que:

Dentre as atividades propostas no ensino/aprendizagem de língua, a produção textual em escrita da língua portuguesa é a que o surdo chega em sala de aula com mais limitações. (...) Os problemas são do tipo: pequeno repertório vocabular, baixa compreensão da estrutura do gênero, trauma no processo e grande uso do processo de interlíngua. (Alves, 2020, p. 113)

No entanto, observa-se que o desafio da leitura e escrita na língua portuguesa para pessoa surda, passou a ser um objetivo de todos os educadores que passa a ter a responsabilidade do ensinar com uma garantia de incluir todos no ambiente escolar. Assim, para corroborar Alves (2020, p.18) diz, "o ensino da língua portuguesa para os surdos é um desafio para todos os educadores". Para isso precisa-se utilizar várias estratégias de ensino, e fazer uma adaptação necessário para com o apoio das habilidades da BNCC, assim apresentamos:

A habilidade que a leitura proporciona segundo a BNCC é: 
Mostrar-se interessado e envolvido pela leitura de livros de literatura e por outras produções culturais do campo e receptivo a textos que rompam com seu universo de expectativas, que representem um desafio em relação às suas possibilidades atuais e suas experiências anteriores de leitura, apoiando-se nas marcas linguísticas, em seu conhecimento sobre os gêneros e a temática e nas orientações dadas pelo professor. (BNCC, 2017, p 74).

No que se refere aos alunos surdos, deve-se oferecer a estes a possibilidade de conhecer diversas formas de produções culturais e nesse caso estamos trabalhando com filme (cinema) e a leitura de resenhas críticas (literatura). É um trabalho que proporciona meios culturais diferentes de se trabalhar tornando o processo de ensino e aprendizagem mais rico e dinâmico.

Ler é sinônimo de se adquirir conhecimento e, portanto, a leitura deve se fazer presente em nossas vidas e deve se tornar um hábito diário para quem não o adquiriu ainda. Nesse sentido, Koch e Elias (2015, p. 11) afirmam que "há lugar, no texto, para toda uma gama de implícitos, dos mais variados tipos, somente detectáveis quando se tem, como pano de fundo, o contexto sociocognitivo dos participantes da interação.” Essa concepção de leitura de maneira interacional da língua pressupõe que os sujeitos são vistos como sujeitos ativos e através do diálogo constroem seu próprio lugar de interação.

Como também é uma das competências de Língua Portuguesa para o ensino fundamental:

Ler, escutar e produzir textos orais, escritos e multissemióticos que circulam em diferentes campos de atuação e mídias, com compreensão, autonomia, fluência e criticidade, de modo a se expressar e partilhar informações, experiências, ideias e sentimentos, e continuar aprendendo (BNCC, 2017, p. 87).

Por isso que defendemos que a leitura de resenhas críticas de filmes pode funcionar como uma ferramenta para o desenvolvimento de habilidades de leitura do aluno surdo como também do ouvinte em Língua Portuguesa.

Nessa perspectiva, o produtor de uma resenha crítica de filmes, ao escrevê-la, deve ter o conhecimento necessário sobre o gênero, e, a partir deste estabelecer uma comunicação, para isso, ele ter adquirido as habilidades suficientes, ao longo do seu processo de formação, ou seja, é preciso adquirir conhecimento teórico sobre a leitura e a produção de textos, como encontramos em Antunes (2003, p. 40), "não pode haver uma prática eficiente sem fundamentação num corpo de princípios teóricos sólidos e objetivos". Assim como aponta a BNCC:

Produzir textos em diferentes gêneros, considerando sua adequação ao contexto produção e circulação - os enunciadores envolvidos, os objetivos, o gênero, o suporte, a circulação -, ao modo (escrito ou oral; imagem estática ou em movimento etc.), à variedade linguística e/ou semiótica apropriada a esse contexto, à construção da textualidade relacionada às propriedades textuais e do gênero), utilizando estratégias de planejamento, elaboração, revisão, edição, reescrita/redesign e avaliação de textos, para, com a ajuda do professor e a colaboração dos colegas, corrigir e aprimorar as produções realizadas, fazendo cortes, acréscimos, reformulações, correções de concordância, ortografia, pontuação em textos e editando imagens, arquivos sonoros, fazendo cortes, acréscimos, ajustes, acrescentando/ alterando efeitos, ordenamentos etc. (BNCC, 2017, p. 143).

Como podemos observar, a BNCC trata da produção de texto que se adequem ao contexto e que tenham um planejamento, ou seja, quem escreve um texto deve estar consciente de seu papel conforme as especificidades desse gênero textual.

Nessa mesma linha de raciocínio, Koch e Elias (2010) defendem que a escolha do gênero deve estar em consonância com os objetivos visados, o lugar social e os papéis dos participantes. Desta forma, um produtor de resenhas críticas deve ter o conhecimento estrutural do gênero e como utilizar os elementos que fazem parte de uma resenha crítica. Ter argumentos sobre o produto cultural, fazendo uma avaliação criteriosa, mas respeitosa mesmo que sua avaliação não seja favorável ao filme. 


\section{Discussão}

Segundo Marconi e Lakatos (2003), a resenha é uma descrição minuciosa que compreende certo número de fatos. Resenha crítica é a apresentação e a análise do conteúdo de uma obra. Consiste na leitura, no resumo, na crítica e na formulação de um conceito de valor da obra resenhada feitos pelo resenhista.

No que se refere ao gênero resenha, Bakhtin (2003), refere que tal gênero insere-se nos gêneros discursivos secundários, ou seja, aqueles que constituem situações comunicativas mais complexas e mais elaboradas, no caso da resenha crítica, esse gênero cumpre a função de auxiliar no processo de ensino/aprendizagem da escrita argumentativa, e em especial neste estudo, poderá ser utilizado como recurso para o desenvolvimento das habilidades de leitura do aluno surdo, como também, poderá aflorar nele a criticidade que é tão pertinente nas resenhas críticas de filmes.

Para escrever uma resenha é necessário, antes de tudo, conhecer a obra a fim de resumi-la e, em seguida, apresentar seu ponto de vista, ou seja, uma argumentação referente ao texto original. Para tanto, a escrita desse gênero textual, pressupõe uma leitura atenta, com questionamentos que fundamentem o posicionamento enquanto resenhista do tex to lido (MACHADO, 2004).

É importante destacar que uma das competências gerais da educação "argumentar com base em fatos, dados e informações confiáveis, para formular, negociar, defender ideias e pontos de vista" (BNCC, 2017, p. 6) e a leitura de resenhas críticas proporciona a leitura de textos em que estão presentes estes elementos.

No nosso caso, trabalharemos com a resenha crítica de filmes, então os produtores destas resenhas são pessoas que antes assistiram ao filme e através desse gênero textual emitiram sua opinião sobre eles. Só podemos escrever sobre aquilo que assistimos na sua integralidade e não o que ouvimos das pessoas a respeito dos filmes.

Enquanto professores, nós devemos preparar o estudante, seja ele surdo ou não, para o processo de escrita, portanto, como assevera Silva (2009, p. 03) "no processo de ensino-aprendizagem da resenha é essencial instrumentalizar os estudantes para que ele desenvolva sua competência argumentativa". Proporcionar a estes, a leitura de resenhas críticas de filmes, é, possivelmente, uma forma de levar a eles, o conhecimento de como os argumentos são construídos na defesa de um ponto de vista sobre este produto cultural que são os filmes.

Não é de qualquer forma que se produz uma resenha, deve-se ter todo um trabalho, isto é, produzir com atenção. É imprescindível que o produtor tenha conhecimento da obra que será objeto da resenha crítica. Conforme Machado (2004, p. 116) quando se faz uma resenha sobre a obra de alguém, é importante seguir algumas regras de polidez para evitar agredir o autor da obra resenhada. Deve existir o respeito e, para tanto, podemos usar vários recursos linguísticos. Dentre eles, temos: 1. Uso de expressões que atenuam as opiniões, como parece-me; $2 \mathrm{O}$ uso de alguns tempos verbais que também tem a função de atenuar o que está sendo dito como: futuro do pretérito; $3 \mathrm{O}$ uso de adjetivos, substantivos e mesmo advérbios para expressar a opinião do resenhista.

Mesmo quando se critica negativamente algo isso deve ser feito de maneira respeitosa para com o produtor da obra, o respeito deve permear todas as relações e discursos sejam eles orais ou escritos. Não podemos menosprezar o que uma pessoa fez porque temos uma opinião contrária, porque aquilo que não é bom para mim pode ser para outra pessoa.

A produção de uma resenha crítica de filmes deve levar em consideração estes elementos elencados por Machado (2004).

Trabalhar com resenhas possibilita ao estudante perceber que o uso da linguagem e o domínio dos processos de elaboração do gênero resenha os capacita a executar práticas discursivas de leitura e de escrita que proporcionarão ao estudante uma aprendizagem significativa. A produção do gênero discursivo resenha de um filme constitui uma leitura crítica sobre um 
filme previamente visto. Nela, o resenhista estabelece um diálogo intertextual, reescreve, recria e, portanto, ressignifica uma obra cinematográfica e, dessa forma, intervém no mundo ao produzir um novo conhecimento (MASCARELLO, 2013).

$\mathrm{Na}$ resenha crítica de filmes é possível perceber que em suas produções o autor vai trabalhar com enunciados argumentativos que possibilitarão perceber análise da obra em questão sobre uma perspectiva bem particular.

Tal gênero nos possibilita e nos ajuda a decidirmos se a obra em questão é digna de ser assistida, dependendo do que é lido na resenha temos a tendência de assisti-la.

A resenha de Maurício Mellone (2015) é uma das resenhas positivas, pois destaca mais a questão da surdez e a função de intérprete que a personagem Paula (a filha) tem na família, porque ela é a única pessoa ouvinte em uma família de surdos. Destacamos a seguir um trecho que pode servir para gerar criticidade dos alunos, pois nele, observamos que uma referência ao fato de que poucas pessoas sabem a língua de sinais.

O espectador não percebe logo de cara que os Bélier são surdos, a vida deles transcorre normalmente na fazenda, com todos executando suas tarefas de maneira corriqueira. Numa das cenas iniciais, a de um nascimento de um bezerrinho, Paula participa ativamente e faz agrados na cria que acaba de nascer. Só na mesa de refeição é que ela assume sua principal função, a de intérprete de todos eles (Mellone, 2015, p. s/p).

Esse trecho da resenha, revela também as responsabilidades que a jovem já assume, tanto no trabalho pesado na fazenda como na comercialização dos queijos; ela precisa se desdobrar na banca que os Bélier mantêm na cidade, pois poucas pessoas sabem a língua dos sinais e a garota precisa ser a intérprete entre os clientes e os pais.

Rojo (2004) afirma que a leitura envolve diversos procedimentos, como por exemplo, cognitivos, afetivos, sociais, discursivas, críticos e linguísticas. Entretanto, para isso, é preciso que o professor articule a leitura com cada situação e cada finalidade de leitura.

No trecho da resenha evidenciado, acima, podemos perceber que o resenhista fala do filme com respeito, conforme preconiza as competências gerais para a educação básica ao agir de forma pessoal e coletivamente com autonomia, responsabilidade, flexibilidade, resiliência e determinação, tomando decisões com base em princípios éticos, democráticos, inclusivos, sustentáveis e solidários ao enfocar os temas abordados no filme e o papel das personagens no mesmo, delineando para nós a função de cada um nesta história linda e emocionante.

Já na resenha de Mauricio, podemos perceber que a resenhista valoriza e utiliza os conhecimentos historicamente construídos sobre o mundo físico, social, cultural e digital para entender e explicar a realidade, continua aprendendo e colaborando para a construção de uma sociedade justa.

Este é um exemplo de resenha crítica positiva porque se respeita a obra e procura valorizá-la enquanto produto cultural.

No que se refere a resenha de Bruno Carmelo (2014), essa é uma das resenhas negativa, porque demonstra falta de conhecimento do próprio resenhista quando usa a expressão "surdos-mudos" para se referir aos surdos da família Bélier. Outra questão que deve ser levantada com os alunos é no trecho que ele escreve:

“A premissa deste filme francês não é muito original: uma garota tímida descobre que tem talento para o canto, o que gera problemas sociais e familiares caso queira seguir esta carreira. Escolher o caminho da música representaria cortar o cordão umbilical, algo doloroso para todos os envolvidos”.

Nesse trecho, podemos questionar que pessoas com deficiência auditiva podem ser independentes, como é algo que toca diretamente na questão dos alunos surdos, eles podem se posicionar de forma crítica a esse respeito. 
Nesse caso, é preciso que o professor encaminhe a leitura como um sistema não pronto, não acabado, porque o texto, hoje não é mais considerado um "simples produto de uma codificação realizada pelo escritor a ser decodificado pelo leitor, bastando a ambos, para tanto, o conhecimento do código utilizado" (Koch; Elias, 2015, p. 33).

Sendo assim, a leitura crítica deve ser viabilizada na perspectiva de que os leitores também atribuem sentido aos textos e, sobretudo, têm a possibilidade de imprimir seus pontos de vistas diante das leituras realizadas. E isso independe de a pessoa ser surda ou não. Como sabemos, de acordo com o decreto 5.626, de 22 de dezembro de 2005, Art. $2^{\circ}$ : a pessoa surda é considerada aquela que, por ter perda auditiva, compreende e interage com o mundo por meio de experiências visuais, manifestando sua cultura principalmente pelo uso da Língua Brasileira de Sinais - Libras (Cristiano, 2020).

Ou seja, a pessoa é surda e não muda, uma vez que o aparelho fonador funciona, essa nomenclatura de surdo-mudo é mais antiga e não é mais aceita pela atualmente. Assim, é preciso respeitar e promover o respeito ao outro, considerando os direitos humanos, o acolhimento e a valorização da diversidade de indivíduos e de grupos sociais, seus saberes, identidades, culturas e potencialidades, sem preconceitos de qualquer natureza". Ao se referir desta forma, o resenhista falta com respeito aos surdos como também deixa de valorizá-los enquanto indivíduos sociais e desrespeita a comunidade surda que é o seu grupo social.

Ter o cuidado e avaliar algo como negativo não implica dizer que se pode faltar ao respeito, por isso que "analisar informações, argumentos e opiniões manifestados em interações sociais e nos meios de comunicação, posicionando-se ética e criticamente em relação a conteúdos discriminatórios que ferem direitos humanos e ambientais" (BNCC, 2017, p. 87) é o que se revela nas competências gerais para a educação básica", diante disso, não ferir e faltar ao respeito com as pessoas envolvidas na obra que objeto da resenha crítica.

Já a resenha de Juliana Varella (2015) é o outro exemplo de uma resenha positiva, pois destaca uma nova visão a respeito do filme, porque ela enfatiza a questão do preconceito do surdo em relação ao falante (a filha) que tem o papel de ser a intérprete da família nas diversas situações, muitas vezes pensando em desistir dos próprios sonhos devido a condição de sua família.

Podemos destacar nessa resenha o seguinte trecho: A independência vem para os dois lados, já que, com a filha falante, os pais e o irmão se acostumaram a ter uma intérprete em todos os momentos. Além disso, a descoberta da voz significará para a mãe, em especial, o confronto com o mundo não-surdo e a necessidade de quebra de um preconceito que ela sempre nutriu, inclusive contra a filha.

Nesse caso, é possível questionar a visão negativa que muitas pessoas ainda têm de pessoas deficientes, ou seja, é possível elencar argumentos que favorecem uma visão crítica a partir do trecho destacado acima. Recorremos a Kleiman (2002), quando a autora reforça a concepção de que a leitura não se limita à mera decodificação dos signos linguísticos, ou seja, precisa-se desenvolver no leitor a capacidade de interação com o texto, com o autor e com os diversos conhecimentos do contexto e experiências que o cercam, com o objetivo de atribuir sentido ao texto lido.

Fazer com que os alunos surdos leiam resenhas críticas de filmes em que os personagens são surdos é mostrar as dificuldades enfrentadas tanto pelos surdos como os ouvintes em seus relacionamentos e que é possível respeitar o outro em suas escolhas.

\section{Conclusão}

Este trabalho buscou analisar a possibilidade de se trabalhar a leitura com resenhas críticas de filmes, envolvendo alunos surdos, no sentido de desenvolvimento das habilidades de leitura dos referidos alunos em aulas de Língua Portuguesa. 
Portanto, o estudo com o tal gênero foi adequado, pois observamos que se trata de um gênero que trabalha com argumentação, por isso, é interessante ser trabalhada no sentido de despertar e gerar a criticidade dos alunos surdos. As leituras realizadas para escrever este artigo, mostraram que o gênero resenha trabalha com práticas discursivas para estudantes surdos, as quais envolvem diálogos ou comentários informais acerca de filmes, o trabalho com resenhas críticas proporciona um foco mais direto na argumentação.

Assim, conclui-se que despertar os estudantes surdos por meio do gênero textual resenha crítica pode ser uma boa estratégia para chamar a atenção desses estudantes, observamos com essa pesquisa que o referido gênero é bem adequado. Dessa forma, o processo de ensino e aprendizagem por meio desse gênero poderá se tornar cada vez mais rico. Além disso, trabalhar com o aluno que tem outra língua materna que não é a nossa, no caso a Língua Portuguesa para os alunos ouvintes e a Libras para os alunos surdos é uma oportunidade ímpar de desenvolvermos outras habilidades e competências e nesse caso é a linguística.

Essa pesquisa mostrou que esse é um tema que tem vários desdobramentos no sentido de que o referido gênero pode ser trabalhado no ensino de Língua Portuguesa para alunos surdos. Diante disso, recomendamos que outras pesquisas sejam desenvolvidas nesse sentido, assim, pretendemos desenvolver uma nova pesquisa que possa apresentar o desenvolvimento dos alunos surdos com a sua L1 que será através de uma produção de uma notícia, pois o surdo tem voz e esta é expressa pelo uso da sua língua materna que é a Libras.

Assim, com apoio de seu conhecimento com a sua Língua materna, o segundo passo será, apresentar a notícia de forma escrita, língua portuguesa como L2. Os resultados serão apresentados de acordo com as necessidades que os alunos surdos tiveram para chegar à conclusão de sua escrita para gênero notícia. Assim concluímos que, para a pessoa surda ter seu s direitos respeitados para a inclusão é, necessário a aquisição de uma segunda língua que é a Língua Portuguesa como L2.

\section{Referências}

Alves, E. de O. (2020). Português como segunda língua para surdos: iniciando uma conversa. Ideia.

Antunes, I. (2003). Aula de português: encontro e interação, Parábola Editorial.

Baktin, M. (2003). Estética da criação verbal. Martins Fontes.

Batista, C. A. M., \& M., M. T. E. (2007). Educação Inclusiva: atendimento educacional especializado em deficiência mental. In: (coord.) Formação continuada a distância de professores para o atendimento educacional especializado: deficiência mental. MEC/SEESP.

Brasil. (1997). Secretaria de Educação Fundamental. Parâmetros curriculares nacionais: língua portuguesa. MEC/SEF.

Brasil. (2000). Lei n ${ }^{\circ}$ 10.098, de 19 de dezembro de 2000. Dispõe sobre a Língua Brasileira de Sinais (Libras).

Brasil. (2002). Lei $\mathrm{n}^{\mathrm{o}}$ 10.436, de 24 de abril de 2002. Dispõe sobre a Língua Brasileira de Sinais - Libras e dá outras providências. <http://www.planalto.gov.br/ccivil_03/leis/2002/110436.htm>.

Brasil (2010). Lei $n^{\circ} 12.319$, de $1^{\text {o }}$ de setembro de 2010. Regulamenta a profissão de Tradutor e Intérprete da Língua Brasileira de Sinais (Libras).

Brasil. (2015). Lei n ${ }^{\circ}$ 13.146, de 6 de julho de 2015. Lei Brasileira de Inclusão da Pessoa com Deficiência (Estatuto da Pessoa com Deficiência).

Brasil. (2017). Base Nacional Comum Curricular (BNCC). Educação é a Base. Brasília, MEC/CONSED/UNDIME. <http://basenacionalcomum.mec.gov.br/images/BNCC_publicacao.pdf>

Carmelo, B. (2014). A Família Bélier: “Todo sonho é possível”. < http://www.adorocinema.com/filmes/filme-214860/>

Cristiano, A. (2018). O que é surdez? <https://www.libras.com.br/o-que-e-surdez>

Cunha, J. N. F. R. G. (2020) Oficinas pedagógicas para uma educação inclusiva. e-book - Toledo, Pr: Instituto Quero Saber. 206 p.

Costa, M. P. P. (2020). Interpretação educacional (Libras-português): subjetividades a partir dos discursos dos intérpretes.

Drumond de Andrade, (1987). C. Brasil. Escritor/Poeta/Cronista.<https://www.citador.pt/frases/a-leitura-e-uma-fonte-inesgotavel-de-prazer-mas-p-carlosdrummond-de-andrade-1210> 
Research, Society and Development, v. 10, n. 15, e297101522558, 2021

(CC BY 4.0) | ISSN 2525-3409 | DOI: http://dx.doi.org/10.33448/rsd-v10i15.22558

Fabrício, N. M. C, S., V. C. B., \& Z., V. B. (2007). Singularidade na Inclusão: estratégias e resultados. Pulso.

Flick, U. (2009) Introdução à pesquisa qualitativa, tradução Joice Elias Costa. (3a ad.), Artmed. 408p. (Série Métodos de Pesquisa).

Goldfeld, M. (2002). A criança surda: Linguagem e cognição numa perspectiva sociointeracionista. (2a ed.), Plexus Editora.

IBGE - Instituto Brasileiro de Geografia e Estatística. Pessoas com deficiência. (2010). <https://educa.ibge.gov.br/jovens/conheca-o-brasil/populacao/20551pessoas-com-deficiencia.html>

Kleiman, A. (2002) Texto e leitor: aspectos cognitivos da leitura. Campinas: Pontes.

Koch, I. V., \& Elias, V. M. (2010) Ler e escrever: estratégias de produção textual. (2a ed.), Contexto.

Koch, I. V., \& Elias, V. M. (2015) Ler e compreender os sentidos do texto. (3a ed.), Contexto.

Machado, A. R. et. al. (2004) Resenha. Parábola Editorial.

Mascarello, J. L. (2013). Pensando sobre a estrutura e organização da resenha crítica. Revista de Letras. v15n17.2384.

Marconi, M. A., \& Lakatos, E. M. (2003). Fundamentos de Metodologia Científica. (5a ed.), Atlas.

Mellone, Maurício. (2015). A Família Bélier: "emocionante filme francês sobre família de surdos".<http://favodomellone.com.br/a-familia-belieremocionante-filme-frances-sobre-familia-de-surdos/familia-belier-450-blog/>

Minayo, M. C. de S. (2008). O desafio do conhecimento. (11a ed.), Hucitec.

Quadros, R. M. de. (2019). Linguística para o ensino superior. (5a ed.), parábola.

Rojo, R. (2004). Letramento e capacidades de leitura para a cidadania. See: CenP.

Ribeiro, Luzimara Lelis (2020). O tradutor intérprete de Libras: análise da legislação vigente. Universidade de Uberaba.

Silva, A. V. L. (2009). A resenha na universidade: ensino e desenvolvimento do aluno como produtor do gênero. V SIGET - Simpósio Internacional de Estudos de Gêneros Textuais. Caxias do Sul-RS, Brasil.

Silva, E. T. (1981) Leitura: algumas raízes do problema. FE/UNICAMP.

Solé, I. (1998) Estratégias de leitura. (6a ed.), Artes Médicas.

Tokarnia, M. (2020), Agência Brasil - <https://agenciabrasil.ebc.com.br/educacao/noticia/2020-09/brasil-perde-46-milhoes-de-leitores-em-quatro-anos.>

Varella, J. (2015) "A família Bélier: "um filme para fugir do óbvio". <https://www.guiadasemana.com.br/cinema/noticia/a-familia-belier-um-filme-para-fugirdo-obvio.> 